\title{
Using Interest Approaches in Instructional Design and Delivery ${ }^{1}$
}

\author{
Brianna N. Shanholtzer, Andrew C. Thoron, J. C. Bunch, and Blake C. Colclasure²
}

Most educators know that it can be challenging to get students motivated to learn at the start of a lesson. The importance of student motivation, academic desire, and engagement is well noted as these factors have been directly linked to students' academic achievement (Larson, 2000). Furthermore, establishing student interest and attentiveness is critical for learning to occur (Keller, 2000). Teachers can organize the start of a lesson to get students ready and excited about learning. One common method to achieve this is starting a lesson through the use of an interest approach. An interest approach uses a brief activity to stimulate students' situational interest toward a topic. Although situational interest is typically held by the learner for a short duration (Renninger \& Hidi, 2002), establishing situational interest at the start of the lesson maximizes students' engagement, motivation, and attentiveness toward the lesson's topic and student learning objectives.

There are many reasons to use an interest approach at the start of a lesson. The following points are just a few examples of why using an interest approach should be an integral component of lesson planning. An interest approach:

1. Gets students ready to learn. It is important to help students focus on learning when they arrive into the classroom. There are often many distractions when students first enter the learning environment. An interest approach can be used to focus students at the start of the lesson, helping them reach a mindset that is open and ready to learn. Interest approaches can be designed to review previous material and to prepare students to think about what they are going to learn next.

2. Aids in organizing the lesson. An interest approach can help structure a lesson. An interest approach should be designed to capture students' initial interest in the lesson. While student interest is captured through the delivery of an interest approach, teachers should also present student learning objectives. As a result, students will be better prepared for the lesson by understanding teacher expectations and educational goals.

\section{Enhances students' understanding of abstract ideas.} Students need to be able to relate what they are learning to the real world. Interest approaches can be designed to help students understand the importance of what they are learning by relating an abstract idea to a concrete rationale of the topic's importance. Students who are able to see the usefulness of what they are learning are more likely to be engaged during the lesson.

\section{Components of an Interest Approach}

Interest approaches can be organized in many ways. However, several components of a well-planned and well-delivered interest approach remain central to fostering students' engagement, motivation, and attention toward the

1. This document is AEC671, one of a series of the Department of Agricultural Education and Communication, UF/IFAS Extension. Original publication date May 2019. Visit the EDIS website at https://edis.ifas.ufl.edu for the currently supported version of this publication.

2. Brianna N. Shanholtzer, graduate student; Andrew Thoron, associate professor; J. C. Bunch, assistant professor; and Blake C. Colclasure, former graduate student, Department of Agricultural Education and Communication; UF/IFAS Extension, Gainesville, FL 32611.

The Institute of Food and Agricultural Sciences (IFAS) is an Equal Opportunity Institution authorized to provide research, educational information and other services

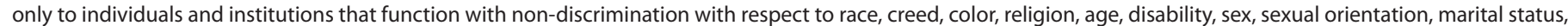

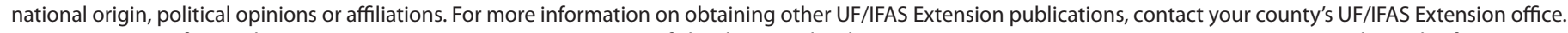
U.S. Department of Agriculture, UF/IFAS Extension Service, University of Florida, IFAS, Florida A \& M University Cooperative Extension Program, and Boards of County Commissioners Cooperating. Nick T. Place, dean for UF/IFAS Extension. 
content of a lesson. When creating an interest approach, it is important to include specific components in order to maximize student impact. These components include but are not limited to:

1. Attention Grabber: The interest approach should be designed to capture students' initial interest. There are many types of attention grabbers that can be used as an interest approach to build students' situational interest. Examples of specific techniques for interest approaches will be discussed in the following section. However, note that the duration of the interest approach should be short, usually not exceeding five to ten minutes.

2. Student Connection: The interest approach should be learner centered. A well-designed interest approach takes characteristics of learners into consideration. Students should be able to see personal relevance of the lesson's topic through the interest approach. Furthermore, the interest approach can connect what students learned previously in the course to what they are going to learn.

3. Appeal to Multiple Learning Styles: Students approach learning in many different ways (Cassidy, 2004). Some learners are more likely to learn through kinesthetic activities, while other learners may appreciate visual representations. Using a variety of activities that include attention grabbers pertaining to different learning modalities can increase student interest for students who learn best in different ways. For example, a visual-spatial learner's interest may be captured by showing an intriguing image, while for a learner strong in linguist skills, a perplexing short story may be more effective.

\section{Connection between Yesterday's Lesson and Today's}

Lesson: Remind students of what they learned previously and connect that to what they are going to learn next. This can be something as simple as saying, "Yesterday we learned about the dairy industry, and today we are going to learn about the impact the dairy industry has on our economy.'

\section{Presentation of Learning Objectives: Get into the} pattern of sharing learning objectives with your students. An ideal time to share each lesson's learning objectives with your students is directly after presenting the interest approach, because student engagement and attentiveness is high. Each lesson's interest approach should be directly related to the learning objectives of the lesson.

\section{Techniques for Interest Approaches}

When planning an interest approach, many different techniques can be used to create learners' situational interest. No matter the technique used, the duration of the technique should be short (e.g., five minutes) and should be directly related to the topic of the forthcoming lesson. The following are examples of commonly used techniques for creating an interest approach.

1. Video Clip: A short, high-quality video clip related to the lesson may spark student interest. Video clips that explore debatable issues, express opinions on a topic, raise questions, share personal narratives, or demonstrate shocking statistics can engage students toward a specific topic. Short video clips from easily accessible sources such as YouTube can spark initial student-led conversation on the topic of the day. Follow a video clip by leading a quick student discussion and sharing student learning objectives.

- Here is an example of a video that would serve as a good interest approach for the ice cream scenario below: https://www.youtube.com/watch?v=Vlb4mfQv6-s.

2. Personal Story: Sharing stories has long evoked student interest. Short personal stories about a lesson's topic, such as the teacher's own story or that of a guest speaker, can draw learners' attention to the importance of the topic at hand. Sharing a personal story about a topic allows the teacher to connect with students in a more informal way while creating students' situational interest in the topic of the lesson.

3. Perplexing Question: Raising a perplexing question to the class is perhaps one of the easiest interest approach techniques to implement. A well-developed and thoughtout question can generate a large amount of student discussion and debate, which leads to students' excitement about the lesson's topic. There are many strategies to deliver a perplexing question; one is to have students explore their own thoughts first through writing out their own response to the question, followed by discussing their thoughts with a partner, and then discussing their responses with the entire class. This technique is called think-pair-share.

4. Case Study: A case study provides a realistic example of how a lesson's topic can develop to become a central issue in the real world. A quick case study allows students to associate what they are going to learn with events that 
have occurred (or could occur) in real life. Case studies can foster student discussion, debate, and interest in a lesson's topic.

5. Demonstration: A short demonstration is a good strategy for capturing students' initial interest. Students who are strong auditory and visual learners will enjoy a quick demonstration, especially when the demonstration includes something unique or unexpected. Make sure to lead a quick student discussion after the demonstration and to share learning objectives for the lesson.

6. Intriguing Picture: An old saying is that a picture is worth a thousand words. Showing a photograph of something unique or intriguing can promote student interest and discussion. An intriguing picture can be paired with a perplexing question about the picture to maximize student engagement. A quick internet search can yield many appropriate pictures on a variety of topics.

7. Scenario: Similar to a case study, proposing a scenario to students can relate a lesson's topic to real-world events, creating unique student discussion and engagement. A scenario can place students into a predicament or ask students for recommendations regarding a specific situation.

8. News Article: Subjects that make the news are typically ones that gain the attention of viewers. Showing a relevant news article that discusses a lesson's topic could make a great interest approach. Have students quickly listen or read the news article and have students discuss their opinions and thoughts on the topic. Follow this student-led conversation by presenting the lesson's student learning objectives.

\section{Interest Approaches in Formal Education: An Example}

Mrs. Smith is teaching her students about the dairy industry. Yesterday her students learned about the dairy industry and the process that farmers go through when milking cattle. Today her students are going to learn about how this milk is transformed into ice cream. Below is Mrs. Smith's interest approach:

"I love the summertime! One of my favorite things to do during the summer when it's very hot outside is to sit down and enjoy a nice, cold snack. My favorite summer treat is ice cream! Who else enjoys ice cream?" After students raises their hands Mrs. Smith will then ask a few students to share their favorite flavors. "Do you ever wonder how this delicious treat ends up in the grocery store? It's important for us as consumers to understand the process that our food products go through to get to the grocery store. Yesterday we learned about the dairy industry and the process that farmers go through when milking cattle, and today we are going to learn about how this milk is transformed into ice cream."

\section{Interest Approaches in Non-Formal Education: An Example}

Mary is teaching an ongoing course to beginning dairy farmers. Last week Mary taught them about the importance of calf nutrition. This week Mary is teaching about the economic benefit that using a calf-milk pasteurizer can provide dairy farmers.

Mary will ask, "When running a business, what are some of your goals?" Mary will then entertain answers to this question until someone responds, "to make money." "Exactly! Most of us run a business because we want to make money. Last week we learned about calf nutrition, and today we are going to learn about a technique that can increase profits on dairy farms. Specifically, we are going to learn about calf-milk pasteurizers and how they can help increase our profits."

\section{Conclusion}

Motivating students at the beginning of a lesson can sometimes be a challenging task. Stimulating students' situational interest can increase student motivation, interest, and engagement throughout a lesson. Through the use of an interest approach at the beginning of a lesson, an instructor can organize the lesson, prepare students to learn, and increase students' understanding of abstract ideas. When designing an interest approach, an instructor should consider the following components: using an attention grabber, connecting with students, appealing to multiple learning styles, connecting yesterday's lesson to today's lesson, and presenting the objectives for the lesson. The instructor should also consider using one of the many techniques provided in this article. By incorporating an interest approach at the beginning of every lesson, an instructor could increase their efficacy as an instructor and engage more students in the topics taught. 


\section{References}

Cassidy, S. (2004). Learning styles: An overview of theories, models, and measures. Educational Psychology, 24(4),

419-444. doi:10.1080/0144341042000228834

Keller, J. (2000). How to integrate learner motivation planning into lesson planning: The ARCS model approach [Scholarly project] Florida State University. Retrieved from http:// apps.fischlerschool.nova.edu/toolbox/instructionalproducts/itde8005/weeklys/2000-Keller-ARCSLessonPlanning. pdf

Larson, R. W. (2000). Toward a psychology of positive youth development. American Psychologist, 55(1), 170-183. doi:10.1037/0003-066X.55.1.170

Renninger, K. A., \& Hidi, S. (2002). Student interest and achievement: Developmental issues raised by a case study. In A. Wigfield \& J. S. Eccles (Eds), A Vol. in the educational psychology series. Development of achievement motivation (pp. 173-195). Academic Press, San Diego, CA. 